\title{
Local gene transfection in the cochlea (Review)
}

\author{
LI XIA and SHANKAI YIN
}

\begin{abstract}
Department of Otolaryngology, The Sixth People's Hospital Affiliated to The Shanghai Jiao Tong University, Otolaryngology Institute of The Shanghai Jiao Tong University, Shanghai 200233, P.R. China
\end{abstract}

Received August 6, 2012; Accepted December 13, 2012

DOI: $10.3892 / \mathrm{mmr} .2013 .1496$

\begin{abstract}
There is much interest in the potential application of vector-induced gene therapeutic approaches to several forms of hearing disorders due to the poor efficacy of existing treatments. The cochlea is an ideal site for local gene transfection due to its anatomical encapsulation and fluid flow within its ducts. However, this requires the development of novel technologies in materials science and microbial supply vectors for target gene delivery. This review focuses on the introduction of various viral and non-viral vectors as well as injection approaches to transfecting cochlear cells in vivo. Finally, the perspective of local gene therapy was discussed. Therapeutic approaches using local gene transfection may provide a means of cochlear cell and tissue protection and treatment in cases of exogenous hearing loss and endogenous disorders.
\end{abstract}

\section{Contents}

1. Introduction

2. Principles of gene transfection in the cochlea

3. Viral vectors

4. Non-viral vectors

5. Injection approaches

6. Future directions

\section{Introduction}

The cochlea is a highly differentiated and anatomically isolated sensory organ located within the temporal bones of mammals, including humans. The hearing function of the cochlea is mainly dependent on the performance of outer and inner hair cells in the organ of Corti and spiral ganglion neurons (SGNs) in the Rosenthal's canal. These hair cells convert sound signals into electrical signals, which are delivered to the auditory pathway of the brain by SGNs along the auditory nerve.

Correspondence to: Professor Shankai Yin, Department of Otolaryngology, The Sixth People's Hospital Affiliated to The Shanghai Jiao Tong University, Otolaryngology Institute of The Shanghai Jiao Tong University, Shanghai 200233, P.R. China E-mail: yinshankai@china.com

Key words: transfection, cochlea, non-viral vector, viral vector
However, the hair cells of the organ of Corti as well as SGNs of the Rosenthal's canal are terminally differentiated cells, and their failure to recover or regenerate following exposure to ototoxic insults, including chemicals and noise, as well as aging, results in irreversible hearing loss in mammals (1-4). Despite advances in the development of neuroprotective drugs, no clinically effective means of repairing or preventing acoustic dysfunction are available as yet (5-7).

The cochlea is a relatively isolated structure anatomically. Although it is difficult for systemically delivered drugs to cross the blood-labyrinth barrier and enter the inner ear, locally injected drugs can be concentrated in the cochlear lymph fluid $(8,9)$. There has been marked progress in target gene identification as well as vector preparation technologies, thus raising the potential for local gene transfection into the cochlea.

More than 90 genes affecting inner ear development have been identified to date, of which 19 are involved in non-syndromic deafness. Viral and non-viral vectors have been experimentally applied to the cochlea using different approaches (10-13). Careful characterization of the mechanisms underlying dysfunctions, such as presbycusis and genetic deafness, is likely to expand the horizons of this novel therapeutic modality. Thus, the number and types of cases to which gene transfection can be applied for the treatment of chronic degenerative disorders and congenital diseases of the ear using gene modification approaches is likely to increase.

\section{Principles of gene transfection in the cochlea}

Local gene transfection involves the insertion, alteration or removal of genes in target tissues using a viral or non-viral vector to drive or inhibit the expression of a functional protein (14-16).

The most evident advantage of local gene transfection into the cochlea is the steady and long-term expression and effect on the target area, which shows marked contrast to the effects of cytokine treatment (17). Exogenous expression of the X-linked inhibitor of apoptosis protein (XIAP) gene delivered by an adeno-associated virus (AAV) vector and of the neurotrophin gene by an adenoviral (Adv) vector was able to maintain long-term effects in cochlear cells and protect against deafness $(14,18)$. However, target gene introduction by a Herpes simplex virus (HSV) vector showed poor transfection efficacy in the inner ear $(19,20)$.

The safety of gene transfection should also be taken into consideration. AAV is an ideal vector due to its low antigenicity. Hydroxyapatite (HAT) nanoparticles also represent a vector 
Table I. Methods used to examine the characteristics of the cochlea pre- and post-gene transfection.

\begin{tabular}{ll}
\hline Examination & \multicolumn{1}{c}{ Methods } \\
\hline Electrophysiology & \\
Outer hair cell (OHC) & Cochlear microphonic (CM), otoacoustic emission (OAE) \\
Inner hair cell (IHC) & Compound action potential (CAP) \\
Spiral ganglion neurons (SGNs) & Compound action potential (CAP) \\
Auditory pathways & Auditory brainstem responses (ABR), \\
& electrical auditory brainstem responses (EABR) \\
Single neuron & Compound action potential (CAP) \\
Staining & \\
Hair cells & Silver nitrate, hematoxylin-eosin (HE), phalloidin-TRITC and DAPI staining \\
SGNs & Prussian blue and DAPI staining \\
Nerve fibers & Anti-neurofilament 200 (NF200) antibodies \\
Observation (microscopy) & \\
Light & Surface preparation, paraffin section, semithin section \\
Fluorescence & Surface preparation, frozen section \\
Laser scanning confocal (LSCM) & Surface preparation, frozen section \\
Scanning electron & Sample coated by conducting material \\
Transmission electron & Ultrathin section \\
\hline
\end{tabular}

DAPI, 4'-6-diamidino-2-phenylindole.

free from the risk of biological disaster (21). By contrast, the application of HSV and Adv vectors has been restricted due to their potential immunogenicity and cytotoxicity $(22,23)$. In addition, the injection procedure was shown to negatively affect the cochlea. Injection by cochleostomy into the scala media or scala tympani causes irreversible electrophysiological and morphological damage to the cochlea $(24,25)$. The methods used to examine cochlear characteristics pre- and post-gene transfection are presented in Table I.

Approximately 45 deafness-related genes have been identified for non-syndromic hereditary hearing loss, and another 30 genes associated with syndromic hearing loss have been identified $(26,27)$. The expression of exogenous genes may be used to rescue, replace or silence mutant loci $(28,29)$. The introduction of genes such as glial cell line-derived neurotrophic factor (GDNF), Bcl-2 and XIAP was shown to have protective effects against ototoxic insults, including chemicaland noise-mediated injury (30-32). Moreover, mouse atonal homolog 1 (Math 1) and human atonal homolog 1 (Hath 1) were shown to induce the regeneration of hair cells in the organ of Corti and utricular maculae $(16,33)$.

In addition, the efficacy of transfection for various vectors in subjects should be considered. Previous studies showed that most transfected cells were located in the basal turn of the cochlea or in the basilar membrane $(34,35)$.

\section{Viral vectors}

$A d v$ vectors. The first studies of cochlear gene transfection utilized an Adv vector composed of a linear DNA molecule $\sim 35 \mathrm{~kb}$ in length. Adv vectors may be generated at high titers and are able to accommodate large (8-kb) DNA inserts. They have the advantage of not requiring cell division for transfec- tion and may be used successfully for the transfection of the terminally differentiated cells in the mammalian inner ear. Adv vectors have been shown to effectively transfect hair cells, and a transfection efficacy of $\sim 90 \%$ in the inner hair cells (IHCs) and 50\% in the outer hair cells (OHCs) and SGNs has been observed in vivo and in vitro (36-39).

First-generation E1', E3- replication-deficient Adv vectors showed cytotoxicity and the induction of an immune response to cochlear hair cells within 8-10 days of transfection $(23,39,40)$. The hair cell lesions induced by E1', E3 ${ }^{-}$replication-deficient Adv vectors are inhibited by immunosuppression using glucocorticoids, while morphological evidence indicates that hair cells remained intact following the injection of glucocorticoids prior to Adv vector treatment (41). Second-generation Adv vectors with deletions in the E1, E2b and E3 regions were introduced into trials of cochlear injection and functional lesions in the cochlea were delayed until 28 days following transfection of the virus. This was suggested to be due to a delayed immune response, which was eliminated using gutted adenoviral vectors with deletions in E1, E2b, E3 and/or pol or another locus (39). The current focus of Adv vector development is on the elimination of excess viral genes to minimize host immune responses and cytotoxicity.

$A A V$ vectors. AAVs consist of a single-stranded DNA parvovirus capable of transfecting pre- and post-mitotic cells with no requirement for actively dividing cells. AAVs accommodate DNA inserts 3.5-4.0 kb in length (42). AAVs integrate into the host cell's DNA, usually on chromosome 19, following induction by the viral rep gene. It was reported previously that transfected AAVs may be retained for 6 months and induce stable transgene expression in cochlear cells (43). Moreover, compared with Adv vectors, AAV vectors are based on a 
non-pathogenic human virus that has not been associated with disease and shows less ototoxicity (38).

There are at least 10 AAV serotypes based on amino acid sequence differences in their respective capsid proteins. Of these, AAV serotypes 1-5 are useful for gene therapeutic applications due to their typical tropism and profile in vivo (44). AAVs of serotype 2 have commonly been used to drive the expression of genes in several cochlear cell types, including hair cells, especially OHCs, and supporting cells in the organ of Corti, SGNs in the Rosenthal's canal, cells of the spiral limbus and spiral ligament and sensory and supporting cells of the crista ampullaris (45-47). AAVs of serotype 5 exhibited high transfection efficacy in SGNs, but failed to transfect hair cells, while AAV1 and AAV7 showed good transfection efficacy in cells of the spiral ligament, and expression driven by AAV5 and AAV8 was especially apparent in Claudius cells (48). These phenomena may be closely correlated with the expression of co-receptors to various virus serotypes on the target cell surface $(49,50)$. However, it is difficult to produce AAV vectors in high titers.

Additionally, the application of mutant AAVs needs to be examined. A recombinant AAV vector with mutations in capsid surface-exposed tyrosine residues showed a 10-fold increase in transfection efficacy in HeLa cells, and a 30-fold increase in murine hepatocytes in vitro compared with tyrosine-phosphorylated AAV vectors (51). This study indicates potential for the development of a high-efficacy transfection system at a low virus dose that is also an ideal candidate for use in human gene therapy (Fig. 1).

$H S V$ vectors. HSV is a DNA virus with a $152-\mathrm{kb}$ double-stranded DNA genome, which may be used to transfect cells of neuronal origin. This type of vector is easy to produce and capable of carrying large DNA inserts. HSV type I has generally been used to transfect cochlear cells. HSV-1-linked NT-3 has been used successfully for the stable transfection of SGNs and for protection against the ototoxicity of cisplatin (52). However, HSV vectors are not the preferred approach for cochlear transfection due to their low transfection efficacy in cochlear cells (20). In addition, there are concerns about the apparent immune response and inflammation induced by viral infection of the inner ear $(53,54)$. Investigation of HSV for cochlear applications remains in the developmental stage, yet these vectors show potential for promoting the survival of neural and neural-derived cells.

Lentivirus vectors. Lentiviruses, such as human immunodeficiency virus, may be used as retroviral vectors to transfect dividing as well as non-dividing cells (55). Although stable protein expression mediated by a lentivirus vector was reported in rat brain without observable toxicity for 6 months (56), the efficacy of transfection into cochlear cells was rather poor in vivo and in vitro. Lentivirus vectors show a narrower distribution throughout the cochlea compared with AAV and Adv vectors. The results of previous in vivo and in vitro studies indicated an intact cellular and tissue cytoarchitecture within lentivirus-infused cochlea and an absence of inflammation or pathological changes (57). Lentiviruses may be suitable as vectors for the transfection of neurotrophins and other protective factors into the cochlea.

\section{Non-viral vectors}

Liposomes. Positively charged (cationic) liposomes coupled with a negatively charged (anionic) integrated target gene are able to bind the plasma membrane of target cells and release the gene into the cytoplasm (58). The genes delivered by liposomes have been shown to be incorporated into the genome of the host, with the encoded protein expressed for only 14 days in the neurosensory epithelia and surrounding tissues of the cochlea in guinea pigs (59). Studies of cationic liposomes have demonstrated a wide distribution of the reporter gene in hair cells and supporting cells in guinea pigs, and in the spiral ligament, Reissner's membrane and SGNs in mice $(59,60)$. However, liposomes may affect the physiological activity of cells, such as inhibition of the mitochondrial inner membrane, protein kinase $\mathrm{C}$ and ATPase activity, resulting in cytotoxicity (61-63). Thus, liposome vectors may be suitable for gene transfection when expression is required only for a short time.

$H A T$. Polylactic/glycolic acid was the first nanoparticle vector used to deliver materials to the cochlea (64). However, HAT was the first nanoparticle vector used successfully to transfect cochlear cells (15). The infusion of HAT particles 40-50 nm in length into the cochlea resulted in no significant damage. In addition, the HAT-mediated gene transfection of NT-3 has been shown to have a protective effect against the excitotoxicity of kainic acid in SGNs. Thus, HAT may be a useful candidate for cochlear transfection if the low transfection efficacy $(16 \%$ in HeLa cells) associated with these nanoparticles can be improved (21).

Hemagglutinating virus of Japan envelope (HVJ-E). HVJ-E vector is a non-viral second generation HVJ vector, which was first used for gene transfection into the central nervous system (65). It is relatively easy to produce HVJ-E and these vectors show higher fusion activity compared with first-generation HVJ-liposome vectors. An HVJ-E vector combining hepatocyte growth factor (HGF) injected through the cerebrospinal fluid was shown to approach the cochlea and the expression of HGF prevented kanamycin-induced hearing loss (66). These results indicate that HVJ-E vectors are more efficient compared with other non-viral vectors and safer compared with viral vectors. Thus, they represent another potentially useful therapeutic approach to sensorineural hearing impairment. Table II briefly compares the advantages and disadvantages of the various vector types described above.

\section{Injection approaches}

As the cochlea is surrounded by a bony wall and is isolated due to the blood-labyrinth barrier, direct infusion into the cochlea is usually necessary to achieve transgene expression in cells within this structure (Fig. 2). This is an ideal approach into the cochlea and does not cause damage or at least functional impairment, and which allows easy and convenient manipulation. There are three main approaches to injection into the cochlea: the scala media, the semicircular canals and the scala tympani.

The scala media approach involves injection into the endolymphatic system using a vector able to transfect sensory 

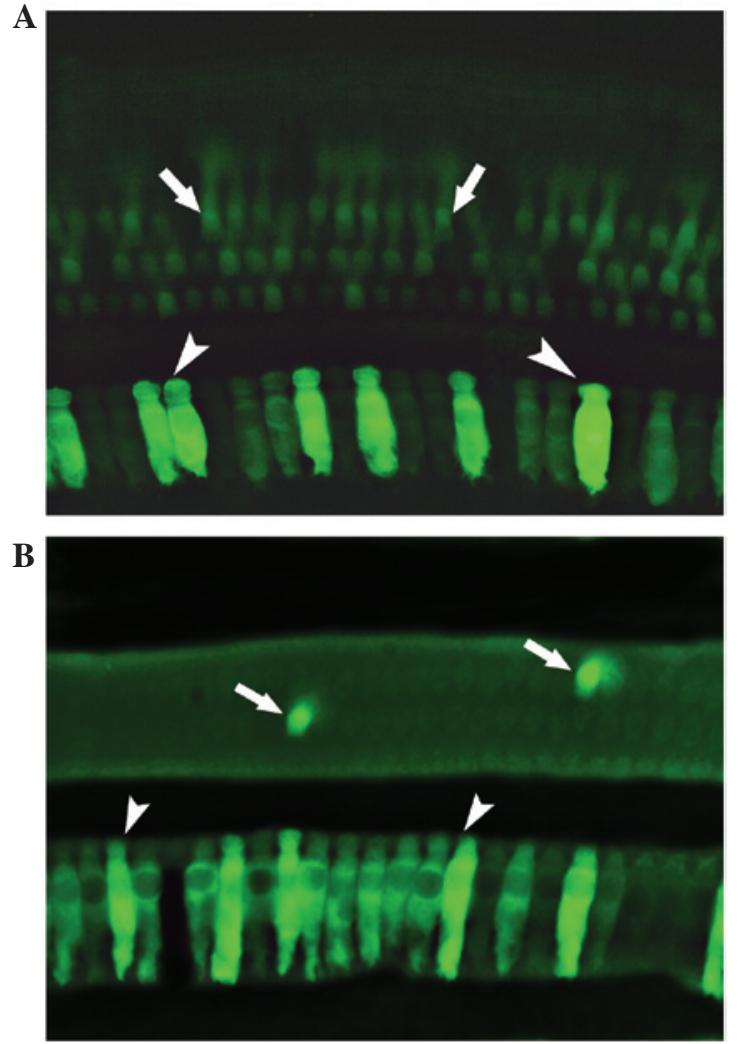

Figure 1. (A) Mut-aav2-GFP $\left(3 \times 10^{12} \mathrm{PFU} / \mathrm{ml}\right)$ showed a high transfection efficacy in both the OHCs and IHCs of guinea pigs by basilar membrane preparation. (B) aav2-GFP $\left(3 \times 10^{12} \mathrm{PFU} / \mathrm{ml}\right)$ showed a high transfection efficacy in IHCs but a lower efficacy in OHCs. Arrows and arrowheads indicate fluorescent signals specifying expression in OHCs and IHCs, respectively. OHCs, outer hair cells; IHCs, inner hair cells

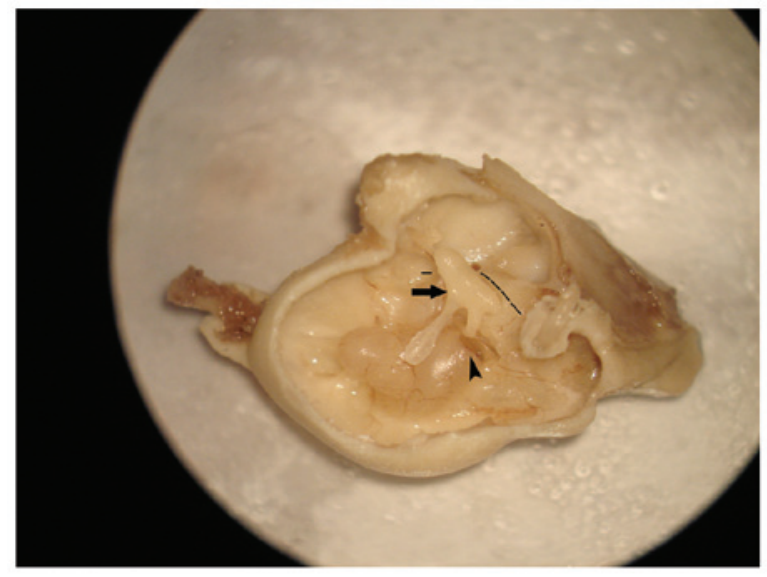

Figure 2. Dissection of a guinea pig acoustic bulla in vitro. A large bulla space is advantageous for operating on the inner ear in cases of cochlear injury. The arrow indicates the malleus and incus; the arrowhead shows the round window niche; the dotted line indicates the spiroid canal.

cells in the organ of Corti (Fig. 3A). However, this pathway is difficult for clinical application due to the complexity of manipulation and possible surgical side-effects, such as disruption of the cochlear structure (the stria vascularis and the spiral ligament) and hearing loss $(67,68)$. Animal studies indicated that surgical exposure from the level of the mandible to the acoustic bulla is required, which may increase the risk
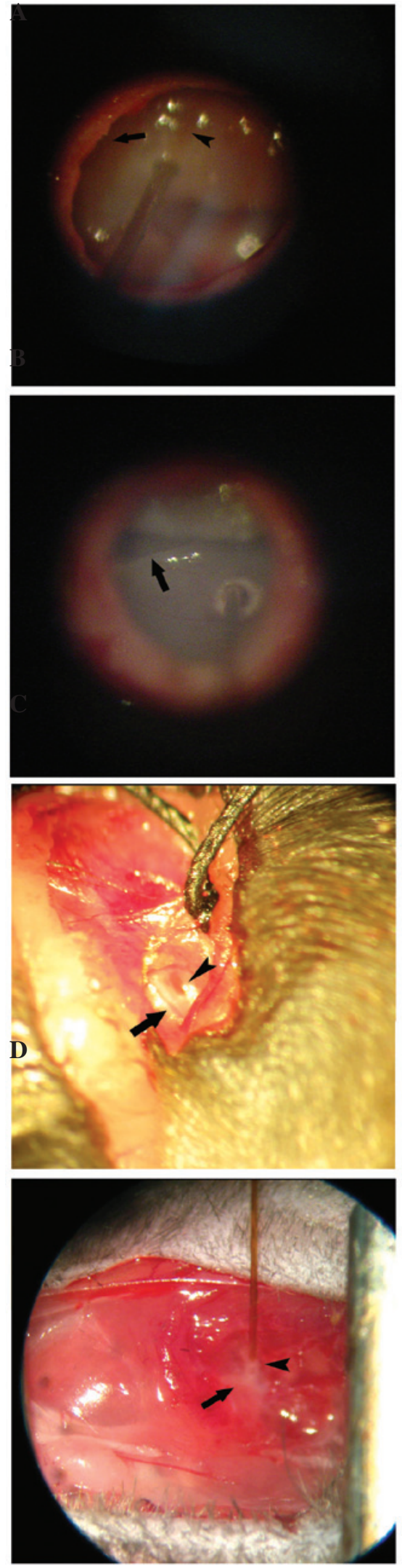

Figure 3. Surgery of needle insertion into the cochlea. (A) Injection into the scala media with the needle crossed the hole in the second turn of the cochlea (arrowhead). (B) Injection into the scala tympani, the puncture site to the first turn of the cochlea was below the RW niche (arrow). (C) Injection into the scala tympani using the trans-RWM approach in a neonatal mouse. The RW niche (arrowhead) and stapedial artery (arrow) were exposed simultaneously. (D) Injection into the scala media by canalis semicircularis posterior in an adult mouse (arrowhead). The arrow shows the canalis semicircularis lateralis. RWM, round window membrane. 
Table II. Overview of the vectors for gene transfection.

\begin{tabular}{|c|c|c|}
\hline Vectors & Advantages & Disadvantages \\
\hline Adv & $\begin{array}{l}\text { Ability to transfect post-mitotic cells } \\
\text { Easy to produce } \\
\text { Large insert size }\end{array}$ & $\begin{array}{l}\text { Limited duration of transgene expression } \\
\text { Immunogenic }\end{array}$ \\
\hline AAV & $\begin{array}{l}\text { Ability to transfect post-mitotic cells } \\
\text { Long-term and stable expression } \\
\text { Nonpathogenic virus }\end{array}$ & $\begin{array}{l}\text { Variable transfection efficiencies } \\
\text { Low gene capacity } \\
\text { Unable to pass freely through the round window membrane } \\
\text { Hard to produce in high titers }\end{array}$ \\
\hline HSV & $\begin{array}{l}\text { Neurotrophic } \\
\text { Easy to produce } \\
\text { Large insert size } \\
\text { Stable expression }\end{array}$ & $\begin{array}{l}\text { Immunogenic } \\
\text { Variable transfection efficiencies }\end{array}$ \\
\hline Lentivirus & Stable expression & $\begin{array}{l}\text { Risk of insertional mutagenesis } \\
\text { Low transfection efficiencies } \\
\text { Cell division required }\end{array}$ \\
\hline Liposomes & $\begin{array}{l}\text { Easy to produce } \\
\text { Large insert size } \\
\text { Nonpathogenic }\end{array}$ & Low transfection efficiencies \\
\hline HAT & $\begin{array}{l}\text { Easy to produce } \\
\text { Large insert size } \\
\text { Nonpathogenic }\end{array}$ & Low transfection efficiencies \\
\hline HVJ-E & $\begin{array}{l}\text { Easy to produce } \\
\text { Large insert size } \\
\text { Nonpathogenic }\end{array}$ & Variable transfection efficiencies \\
\hline
\end{tabular}

Adv, adenoviral; AAV, adeno-associated virus; HSV, herpes simplex virus; HAT, hydroxyapatite; HVJ-E, hemagglutinating virus of Japan envelope.

of functional impairment, and serious threshold shifts and hair cell loss were observed following surgery in animal models $(67,69)$. Thus, this is not the preferred option for the introduction of transgenes into the cochlea from the viewpoint of functional recovery.

Conversely, the scala tympani approach, represented by cochleostomy and the trans-round window membrane (RWM) technique, is a comparatively convenient and simple method for animal experiments as well as clinical application. Cochleostomy (Fig. 3B) may be better than the trans-RWM technique (Fig. 3C) for the administration of accurate volumes and to prevent potential fluid leakage. In addition, there is no evidence of threshold shifts by ABR tests following surgery for cochleostomy infusion $(70,71)$, however, studies of histopathological changes in cochlear cells following cochleostomy should be conducted to ensure the protection of function (24).

Several vectors, including liposomes, Adv vectors and HSV, have been shown to travel into the cochlea from the middle ear space via the RWM, resulting in cochlear cell transfection $(34,72)$. The inflammatory response induced by macrophages and precipitated in the inner ear to such vectors probably enhances their ability to enter the inner ear space due to an increase in permeability of the RWM (73). Conversely, AAVs are unable to traverse the RWM freely without specific treatments to enhance the permeability of the membrane (74). Methods to alter the permeability of the RWM may also be used to enhance the rate of passage of other vectors.

Based on the structure of the basilar membrane, which lacks tight junctions, but consists of fibrils, a homogeneous ground substance and mesothelial cells, vectors in the perilymph space are able to cross the basilar membrane to approach hair cells $(75,76)$. Another pathway into the cochlea involves passage through the habenula perforata to enter the organ of Corti (77).

The semicircular canal approach, also termed canalostomy (Fig. 3D), is used to introduce vectors into the cochlea as well as the vestibular system (78). The semicircular canal is relatively simple to expose and the procedure carries little risk of injuring the cochlea and surrounding blood vessels compared with cochleostomy. However, the main disadvantage of the semicircular canal approach is that it is impossible to determine whether the tip of the needle opens into the endolymphatic compartment or into the perilymph during surgery, and the seal between the bone and the tube is usually ruptured, resulting in leakage of the inner ear fluid and vector suspension. Furthermore, canalostomy was shown to be associated with temporary vestibular function disorders in mice, including adverse effects on circling behavior, head tilt and swimming ability, but they recovered within 2 weeks following surgery (79). 


\section{Future directions}

The future of gene transfection is likely to include improving the properties of vectors to achieve a higher transfection efficacy and cell targeting, refining the methods of gene delivery to minimize lesions to the cochlea, while confirming widespread transfection throughout the cochlea or localized transfection within specific areas.

In addition to treating chemical- and noise-induced hearing loss, gene therapy may be used to improve cochlear implant function. Neurotrophins promote the survival of and delay the degeneration of SGNs. Neurotrophin gene transfection performed in conjunction with cochlear implant surgery may enhance neurite growth to the cochlear implant. The development of cochlear implants with improved performance would improve the quality of life for a number of deaf children and elderly people.

The genes and factors involved in cell fate determination in the sensory epithelium of the inner ear have been explored. Math 1 and Hath 1 have been shown to drive regeneration of hair cells posterior to the lesions induced by ototoxic factors. Further basic investigation of drug delivery in fetal and neonatal animals is likely to facilitate the development of novel methodologies for the effective treatment of genetic diseases.

\section{Acknowledgements}

This study was supported by the China National Funds for Distinguished Young Scientists (grant no. 30925035).

\section{References}

1. Henry KR, Chole RA, McGinn MD and Frush DP: Increased ototoxicity in both young and old mice. Arch Otolaryngol 107: 92-95, 1981.

2. Ishiyama G, Ishiyama A, Kerber $\mathrm{K}$ and Baloh RW: Gentamicin ototoxicity: clinical features and the effect on the human vestibulo-ocular reflex. Acta Otolaryngol 126: 1057-1061, 2006.

3. Eshraghi AA, Frachet B, Van De Water TR and Eter E: Hearing loss in adults. Rev Prat 59: 645-652, 2009 (In French).

4. Fetoni AR, Mancuso C, Eramo SL, et al: In vivo protective effect of ferulic acid against noise-induced hearing loss in the guinea pig. Neuroscience 169: 1575-1588, 2010.

5. Campbell KC, Meech RP, Klemens JJ, et al: Prevention of noiseand drug-induced hearing loss with D-methionine. Hear Res 226: 92-103, 2007.

6. Lee CK, Shin JI and Cho YS: Protective effect of minocycline against cisplatin-induced ototoxicity. Clin Exp Otorhinolaryngol 4: 77-82, 2011.

7. Maniu A, Perde-Schrepler M and Cosgarea M: Protective effect of L-N-acetylcysteine against gentamycin ototoxicity in the organ cultures of the rat cochlea. Rom J Morphol Embryol 52: $159-164,2011$

8. Agrup C, Gleeson $\mathrm{M}$ and Rudge P: The inner ear and the neurologist. J Neurol Neurosurg Psychiatry 78: 114-122, 2007.

9. Swan EE, Mescher MJ, Sewell WF, Tao SL and Borenstein JT: Inner ear drug delivery for auditory applications. Adv Drug Deliv Rev 60: 1583-1599, 2008.

10. Staecker H, Gabaizadeh R, Federoff H and Van De Water TR Brain-derived neurotrophic factor gene therapy prevents spiral ganglion degeneration after hair cell loss. Otolaryngol Head Neck Surg 119: 7-13, 1998.

11. Suzuki M, Yamasoba T, Suzukawa K and Kaga K: Adenoviral vector gene delivery via the round window membrane in guinea pigs. Neuroreport 14: 1951-1955, 2003.

12. Duan M, Venail F, Spencer N and Mezzina M: Treatment of peripheral sensorineural hearing loss: gene therapy. Gene Ther 11 (Suppl 1): S51-S56, 2004.
13. Praetorius M, Pfannenstiel S, Klingmann C, Baumann I, Plinkert PK and Staecker H: Expression patterns of non-viral transfection with GFP in the organ of Corti in vitro and in vivo. Gene therapy of the inner ear with non-viral vectors. HNO 56: 524-529, 2008 (In German).

14. Cooper LB, Chan DK, Roediger FC, et al: AAV-mediated delivery of the caspase inhibitor XIAP protects against cisplatin ototoxicity. Otol Neurotol 27: 484-490, 2006.

15. Jiang M, Zhang YQ, He GX and Sun H: Protective effect of NT-3 gene mediated by hydroxyapatite nanoparticle on the cochlea of guinea pigs injured by excitotoxicity. Zhong Nan Da Xue Xue Bao Yi Xue Ban 32: 563-567, 2007 (In Chinese).

16. Kawamoto K, Ishimoto S, Minoda R, Brough DE and Raphael Y: Math1 gene transfer generates new cochlear hair cells in mature guinea pigs in vivo. J Neurosci 23: 4395-4400, 2003.

17. Ylikoski J, Pirvola U, Virkkala J, et al: Guinea pig auditory neurons are protected by glial cell line-derived growth factor from degeneration after noise trauma. Hear Res 124: 17-26, 1998.

18. Ghilardi JR, Freeman KT, Jimenez-Andrade JM, et al: Sustained blockade of neurotrophin receptors TrkA, TrkB and TrkC reduces non-malignant skeletal pain but not the maintenance of sensory and sympathetic nerve fibers. Bone 48: 389-398, 2011.

19. Michael AE, Collins TD, Norgate DP, Gregory L, Wood PJ and Cooke BA: Relationship between ovarian cortisol:cortisone ratios and the clinical outcome of in vitro fertilization and embryo transfer (IVF-ET). Clin Endocrinol (Oxf) 51: 535-540, 1999.

20. Carnicero E, Garrido JJ, Alonso MT and Schimmang T: Roles of fibroblast growth factor 2 during innervation of the avian inner ear. J Neurochem 77: 786-795, 2001.

21. Frolenkov GI, Belyantseva IA, Kurc M, Mastroianni MA and Kachar B: Cochlear outer hair cell electromotility can provide force for both low and high intensity distortion product otoacoustic emissions. Hear Res 126: 67-74, 1998.

22. Liberman MC, Zuo J and Guinan JJ, Jr.: Otoacoustic emissions without somatic motility: can stereocilia mechanics drive the mammalian cochlea? J Acoust Soc Am 116: 1649-1655, 2004.

23. Ye HB, Shi HB, Wang J, et al: Bilirubin induces auditory neuropathy in neonatal guinea pigs via auditory nerve fiber damage. J Neurosci Res 90: 2201-2213, 2012.

24. El-Badry MM and McFadden SL: Electrophysiological correlates of progressive sensorineural pathology in carboplatin-treated chinchillas. Brain Res 1134: 122-130, 2007.

25. Xia L, Yin S and Wang J: Inner ear gene transfection in neonatal mice using adeno-associated viral vector: a comparison of two approaches. PLoS One 7: e43218, 2012.

26. Landry TG, Wise AK, Fallon JB and Shepherd RK: Spiral ganglion neuron survival and function in the deafened cochlea following chronic neurotrophic treatment. Hear Res 282: 303-313, 2011.

27. Walton JP, Barsz K and Wilson WW: Sensorineural hearing loss and neural correlates of temporal acuity in the inferior colliculus of the C57BL/6 mouse. J Assoc Res Otolaryngol 9: 90-101, 2008.

28. Wang H, Yin S, Yu Z, Huang Y and Wang J: Dynamic changes in hair cell stereocilia and cochlear transduction after noise exposure. Biochem Biophys Res Commun 409: 616-621, 2011.

29. Yang SM, Doi T, Asako M, Matsumoto A and Yamashita T: Optical recording of membrane potential in dissociated mouse vestibular ganglion cells using a voltage-sensitive dye. Auris Nasus Larynx 27: 15-21, 2000.

30. Poirrier AL, Van den Ackerveken P, Kim TS, et al: Ototoxic drugs: difference in sensitivity between mice and guinea pigs. Toxicol Lett 193: 41-49, 2010.

31. Ishimoto S, Kawamoto K, Stöver T, Kanzaki S, Yamasoba T and Raphael Y: A glucocorticoid reduces adverse effects of adenovirus vectors in the cochlea. Audiol Neurootol 8: 70-79, 2003.

32. Wang H, Murphy R, Taaffe D, et al: Efficient cochlear gene transfection in guinea-pigs with adeno-associated viral vectors by partial digestion of round window membrane. Gene Ther 19: 255-263, 2012.

33. Maeda Y, Fukushima K, Kawasaki A, Nishizaki K and Smith RJ: Cochlear expression of a dominant-negative GJB2R75W construct delivered through the round window membrane in mice. Neurosci Res 58: 250-254, 2007.

34. Sun H, Jiang M and Zhu SH: In vitro and in vivo studies on hydroxyapatite nanoparticles as a novel vector for inner ear gene therapy. Zhonghua Er Bi Yan Hou Tou Jing Wai Ke Za Zhi 43: 51-57, 2008 (In Chinese).

35. Lalwani AK and Mhatre AN: Cochlear gene therapy. Ear Hear 24: $342-348,2003$ 
36. Thomas CE, Ehrhardt A and Kay MA: Progress and problems with the use of viral vectors for gene therapy. Nat Rev Genet 4: 346-358, 2003

37. Dimitrov EA and Duckert LG: Morphologic changes in the guinea pig cochlea following cochleostomy - a preliminary scanning electron microscope study. Otolaryngol Head Neck Surg 93: 408-413, 1985.

38. Iizuka T, Kanzaki S, Mochizuki H, et al: Noninvasive in vivo delivery of transgene via adeno-associated virus into supporting cells of the neonatal mouse cochlea. Hum Gene Ther 19: 384-390, 2008.

39. Kesser BW and Lalwani AK: Gene therapy and stem cell transplantation: strategies for hearing restoration. Adv Otorhinolaryngol 66: 64-86, 2009.

40. Newton VE: Aetiology of bilateral sensori-neural hearing loss in young children. J Laryngol Otol Suppl 10: 1-57, 1985.

41. Qu C, Gardner P and Schrijver I: The role of the cytoskeleton in the formation of gap junctions by Connexin 30. Exp Cell Res 315 1683-1692, 2009.

42. Holt JR: Viral-mediated gene transfer to study the molecular physiology of the Mammalian inner ear. Audiol Neurootol 7: $157-160,2002$.

43. Yagi M, Magal E, Sheng Z, Ang KA and Raphael Y: Hair cell protection from aminoglycoside ototoxicity by adenovirus-mediated overexpression of glial cell line-derived neurotrophic factor. Hum Gene Ther 10: 813-823, 1999.

44. Cheng G, Liu L, Wang P, et al: An in vivo transfection approach elucidates a role for Aedes aegypti thioester-containing proteins in flaviviral infection. PLoS One 6: e22786, 2011.

45. Pfannenstiel SC, Praetorius M, Plinkert PK, Brough DE and Staecker H: Bcl-2 gene therapy prevents aminoglycoside-induced degeneration of auditory and vestibular hair cells. Audiol Neurootol 14: 254-266, 2009

46. Shou J, Zheng JL and Gao WQ: Robust generation of new hair cells in the mature mammalian inner ear by adenoviral expression of Hath1. Mol Cell Neurosci 23: 169-179, 2003.

47. Jero J, Mhatre AN, Tseng CJ, et al: Cochlear gene delivery through an intact round window membrane in mouse. Hum Gene Ther 12: 539-548, 2001.

48. Derby ML, Sena-Esteves M, Breakefield XO and Corey DP: Gene transfer into the mammalian inner ear using HSV-1 and vaccinia virus vectors. Hear Res 134: 1-8, 1999.

49. Lei L and Han D: Efficient transduction of spiral ganglion cells using adenovirus type 5 vector in the rat. Acta Otolaryngol 130: 810-814, 2010.

50. Duan ML,Ulfendahl M,Laurell G, et al: Protection and treatment of sensorineural hearing disorders caused by exogenous factors: experimental findings and potential clinical application. Hear Res 169: 169-178, 2002

51. Luebke AE, Foster PK, Muller CD and Peel AL: Cochlear function and transgene expression in the guinea pig cochlea, using adenovirus- and adeno-associated virus-directed gene transfer. Hum Gene Ther 12: 773-781, 2001.

52. Luebke AE, Steiger JD, Hodges BL and Amalfitano A: A modified adenovirus can transfect cochlear hair cells in vivo without compromising cochlear function. Gene Ther 8: 789-794, 2001.

53. Holt JR, Johns DC, Wang S, et al: Functional expression of exogenous proteins in mammalian sensory hair cells infected with adenoviral vectors. J Neurophysiol 81: 1881-1888, 1999.

54. Ishimoto S, Kawamoto K, Stover T, Kanzaki S, Yamasoba T and Raphael Y: A glucocorticoid reduces adverse effects of adenovirus vectors in the cochlea. Audiol Neurootol 8: 70-79, 2003.

55. Li Duan M, Bordet T, Mezzina M, Kahn A and Ulfendahl M: Adenoviral and adeno-associated viral vector mediated gene transfer in the guinea pig cochlea. Neuroreport 13: 1295-1299, 2002.

56. Lalwani A, Walsh B, Reilly P, et al: Long-term in vivo cochlear transgene expression mediated by recombinant adeno-associated virus. Gene Ther 5: 277-281, 1998

57. Stone IM,Lurie DI, Kelley MW and Poulsen DJ: Adeno-associated virus-mediated gene transfer to hair cells and support cells of the murine cochlea. Mol Ther 11: 843-848, 2005.

58. Lalwani AK, Walsh BJ, Reilly PG, Muzyczka N and Mhatre AN: Development of in vivo gene therapy for hearing disorders: introduction of adeno-associated virus into the cochlea of the guinea pig. Gene Ther 3: 588-592, 1996.

59. Lalwani AK, Walsh BJ, Carvalho GJ, Muzyczka N and Mhatre AN: Expression of adeno-associated virus integrated transgene within the mammalian vestibular organs. Am J Otol 19: 390-395, 1998 .
60. Kilpatrick LA, Li Q, Yang J, Goddard JC, Fekete DM and Lang H: Adeno-associated virus-mediated gene delivery into the scala media of the normal and deafened adult mouse ear. Gene Ther 18: 569-578, 2011.

61. Liu Y, Okada T, Sheykholeslami K, et al: Specific and efficient transduction of Cochlear inner hair cells with recombinant adenoassociated virus type 3 vector. Mol Ther 12: 725-733, 2005.

62. Walters RW, Yi SM, Keshavjee S, et al: Binding of adeno-associated virus type 5 to 2,3-linked sialic acid is required for gene transfer. J Biol Chem 276: 20610-20616, 2001.

63. Xiao W, Chirmule N, Berta SC, McCullough B, Gao G and Wilson JM: Gene therapy vectors based on adeno-associated virus type 1. J Virol 73: 3994-4003, 1999.

64. Zhong L, Li B, Jayandharan G, et al: Tyrosine-phosphorylation of AAV2 vectors and its consequences on viral intracellular trafficking and transgene expression. Virology 381: 194-202, 2008.

65. Chen X, Frisina RD, Bowers WJ, Frisina DR and Federoff HJ: HSV amplicon-mediated neurotrophin-3 expression protects murine spiral ganglion neurons from cisplatin-induced damage. Mol Ther 3: 958-963, 2001.

66. Keithley EM, Woolf NK and Harris JP: Development of morphological and physiological changes in the cochlea induced by cytomegalovirus. Laryngoscope 99: 409-414, 1989.

67. Stearns GS, Keithley EM and Harris JP: Development of high endothelial venule-like characteristics in the spiral modiolar vein induced by viral labyrinthitis. Laryngoscope 103: 890-898, 1993.

68. Ailles LE and Naldini L: HIV-1-derived lentiviral vectors. Curr Top Microbiol Immunol 261: 31-52, 2002.

69. Blomer U, Naldini L, Kafri T, Trono D, Verma IM and Gage FH: Highly efficient and sustained gene transfer in adult neurons with a lentivirus vector. J Virol 71: 6641-6649, 1997.

70. Han JJ, Mhatre AN, Wareing M, et al: Transgene expression in the guinea pig cochlea mediated by a lentivirus-derived gene transfer vector. Hum Gene Ther 10: 1867-1873, 1999.

71. Felgner PL, Gadek TR, Holm M, et al: Lipofection: a highly efficient, lipid-mediated DNA-transfection procedure. Proc Natl Acad Sci USA 84: 7413-7417, 1987.

72. Wareing M, Mhatre AN, Pettis R, et al: Cationic liposome mediated transgene expression in the guinea pig cochlea. Hear Res 128: 61-69, 1999.

73. Jero J, Tseng CJ, Mhatre AN and Lalwani AK: A surgical approach appropriate for targeted cochlear gene therapy in the mouse. Hear Res 151: 106-114, 2001.

74. Beavis AD: On the inhibition of the mitochondrial inner membrane anion uniporter by cationic amphiphiles and other drugs. J Biol Chem 264: 1508-1515, 1989.

75. Bottega $R$ and Epand RM: Inhibition of protein kinase $C$ by cationic amphiphiles. Biochemistry 31: 9025-9030, 1992.

76. Datiles MJ, Johnson EA and McCarty RE: Inhibition of the ATPase activity of the catalytic portion of ATP synthases by cationic amphiphiles. Biochim Biophys Acta 1777: 362-368, 2008.

77. Tamura T, Kita T, Nakagawa T, et al: Drug delivery to the cochlea using PLGA nanoparticles. Laryngoscope 115: 2000-2005, 2005.

78. Shimamura M, Morishita R, Endoh M, et al: HVJ-envelope vector for gene transfer into central nervous system. Biochem Biophys Res Commun 300: 464-471, 2003.

79. Oshima K, Shimamura M, Mizuno S, et al: Intrathecal injection of HVJ-E containing HGF gene to cerebrospinal fluid can prevent and ameliorate hearing impairment in rats. FASEB J 18: 212-214, 2004.

80. Ishimoto S, Kawamoto K, Kanzaki S and Raphael Y: Gene transfer into supporting cells of the organ of Corti. Hear Res 173: 187-197, 2002.

81. Yamasoba T, Yagi M, Roessler BJ, Miller JM and Raphael Y: Inner ear transgene expression after adenoviral vector inoculation in the endolymphatic sac. Hum Gene Ther 10: 769-774, 1999.

82. Shibata SB, Di Pasquale G, Cortez SR, Chiorini JA and Raphael Y: Gene transfer using bovine adeno-associated virus in the guinea pig cochlea. Gene Ther 16: 990-997, 2009.

83. Stover T, Yagi $M$ and Raphael Y: Cochlear gene transfer: round window versus cochleostomy inoculation. Hear Res 136: 124-130, 1999.

84. Konishi M, Kawamoto K, Izumikawa M, Kuriyama H and Yamashita T: Gene transfer into guinea pig cochlea using adeno-associated virus vectors. J Gene Med 10: 610-618, 2008.

85. Nomura Y, Hara M and Kurata T: Experimental herpes simplex virus and cytomegalovirus labyrinthitis. Acta Otolaryngol Suppl 457: 57-66, 1989 
86. Weiss MA, Frisancho JC, Roessler BJ and Raphael Y: Viral-mediated gene transfer in the cochlea. Int J Dev Neurosci 15: 577-583, 1997.

87. Nadol JB Jr: Intercellular junctions in the organ of Corti. Ann Otol Rhinol Laryngol 87: 70-80, 1978.

88. Kimura RS: The ultrastructure of the organ of Corti. Int Rev Cytol 42: 173-222, 1975.

89. Fritzsch B, Farinas I and Reichardt LF: Lack of neurotrophin 3 causes losses of both classes of spiral ganglion neurons in the cochlea in a region-specific fashion. J Neurosci 17: 6213-6225, 1997.
90. Griffith AJ, Ji W, Prince ME, Altschuler RA and Meisler MH: Optic, olfactory, and vestibular dysmorphogenesis in the homozygous mouse insertional mutant Tg9257. J Craniofac Genet Dev Biol 19: 157-163, 1999.

91. Kawamoto K, Oh SH, Kanzaki S, Brown N and Raphael Y: The functional and structural outcome of inner ear gene transfer via the vestibular and cochlear fluids in mice. Mol Ther 4: 575-585, 2001. 